\title{
Mikrodenetleyicili İHA Uçuş Test Düzeneği Tasarımı
}

\section{Drone Flight Test System Design with Microcontroller}

\author{
Hüseyin Can Küçüksezer ${ }^{1 *}$, İdris Sancaktar ${ }^{2}$ \\ Geliş / Received: 24/05/2021 \\ Revize / Revised: 23/11/2021 \\ Kabul / Accepted: 02/12/2021
}

\begin{abstract}
öZ
İnsansız hava araçları, sportif ve ticari amaçlı kullanımının yaygınlaşması ile günlük hayatta sıkça rastladığımız cihazlar haline gelmiştir. Teknolojinin de gelişmesi ile üretim yolları kolaylaşmış ev, okul vb. yerlerde hobi, akademik vb. nedenlerle insansız hava araçları üretiminin yapılması daha kolay hale gelmiştir. İnsansız hava aracının üretimi sırasında fark edilemeyen yazılımsal veya donanımsal problem ve hatalar meydana gelebilir. Uçuş parametrelerinin iyi bir şekilde ayarlanamaması, ağırlık merkezinin sapması, elektrik bağlantılarında yaşanabilecek hatalar bunlardan yalnızca birkaç tanesidir. Bunlar ve benzeri sıkça yaşanan durum uçuş aşamasına gelindiğinde insansız hava aracının kaza yapmasına; araca ve çevresindeki canlılara zarar vermesine neden olabilir. Hataların tespiti, dolayısıyla insansız hava aracının zarar görmeden kararlı uçuş sağlayabilmesi için test edilmesini sağlayacak bir sisteme ihtiyaç görülmüştür. Yaptığımız çalışma sayesinde döner kanatlı insansız hava araçları için üç eksen kontrollü (x, y ve z eksenlerindeki denetim) uçuş test düzeneği hazırlanmıştır. Uçuş denetim parametreleri test düzeneği üzerinde bulunan mikroişlemci kontrollü devre ve test sistemi için tasarlanan mobil uygulama sayesinde izlenebilmektedir. Eksen bilgisi "IMU" sensörleri sayesinde elde edilirken uçuş test düzeneğinin akıllı telefon ile olan iletişimi "bluetooth" teknolojisi ile sağlanmıştır. Bu düzenek özellikle proje geliştirme aşamasındaki döner kanatlı insansız hava araçların kontrolü için tasarlanmıştır. Bu uçuş test sistemi ile insansız hava aracı, uçuş esnasındaki temel senaryoları gerçekleştirilebilmektedir. Kalibrasyon hataları, itki sistemindeki dengesizlik, uçuş esnasındaki denge ve kararlılık, ağırlık merkezinin sapması gibi olası durumların uçuş öncesinde gözlemlenmesine imkân sunmaktadır.
\end{abstract}

Anahtar Kelimeler- Insansız Hava Aracı, Uçuş Simülasyonu, IMU Sensörü, Döner Kanatlı İHA

\begin{abstract}
Unmanned aerial vehicles have become daily use devices with the widespread use of sports and commercial use. Production has become easier with the developing technology and due to academic, hobby etc. It has enabled the production of unmanned aerial vehicles in places, such as homes or schools. Some undetected hardware or software problems and errors may occur during the production of unmanned aerial vehicles. Poor adjustments of flight parameters, deviation of centre of gravity, errors that can be encountered in electrical connections are some of the problems. Common situations like these can cause unmanned aerial vehicles to crash; it can damage the vehicle and the living creatures around it. A system was required which can detect the errors hence provide the unmanned aerial vehicles to fly stable without being damage. Thanks to our work, a 3-axis controlled flight test rig has been prepared for rotary wing unmanned aerial vehicles. Flight detection parameters can be observed with the microprocessor-controlled circuit on the test setup and the mobile application prepared for setup. While axis information is obtained with "IMU" sensors, communication between the smartphone and the device is provided
\end{abstract}

1*Sorumlu yazar iletișim: huseyincankucuksezer@gmail.com (https://orcid.org/0000-0003-0144-196X)

Elektrik Elektronik Mühendisliği, Ondokuz Mayıs Üniversitesi, Atakum, Samsun

2İletișim: idris.sancaktar@omu.edu.tr (https://orcid.org/0000-0002-4790-0124)

Elektrik Elektronik Mühendisliği, Ondokuz Mayıs Üniversitesi, Atakum, Samsun 
by "Bluetooth" technology. This setup is specifically designed to control developing rotary wing unmanned aerial vehicles. Unmanned aerial vehicle can simulate the basic scenarios during the flight with this system. It ensures that possible situations, such as calibration errors, imbalance in the propulsion system, balance, and determination during the flight, deviation of centre of gravity are observed before the flight.

\section{Keywords- Unmanned Aerial Vehicles, Flight Simulation, IMU Sensors, Rotary Wing Uav}

\section{GİRIS}

İnsansız hava araçları (IHA) gelişimini hızla sürdürmekte ve büyük ilgi görmektedir. Ülkemizdeki yarışmalar da bireysel olarak İHA üretiminde bir artışa sebep olmuştur. Bu kadar ilgi gören bu araçlar daha test aşamasındayken ya da uçuş esnasında küçük bir hesap hatası yüzünden kaza yapabilmektedir. Bu ve benzer nedenlerden dolayı, İHA'lar için kontrol algoritmalarının ve uçuş denetim parametrelerinin test edilebileceği bir düzeneğe ihtiyaç duyulmaktadır. İnsansız hava araçlarının davranışlarının test edilmesinin deneme yanılma yöntemleri ya da kullanıcı tecrübesine dayanarak yapıldığı bilinmektedir. Akademik düzeydeki çalışmalarda; İHA'ya ait hareket bilgisini, üç eksenli bir düzenek sayesinde İHA'nın dâhili sensörlerinden telemetri yöntemi ile elde eden çalışmalar da mevcuttur $[1,2]$. Ticari çalışmalarda ise, jiroskop modelini temel alarak insansız hava aracını merkez noktasında konumlandıracak bir ürün gerçekleştirilmiştir. Ayrıca insansız hava aracının hareket bilgisini, araç üzerinde bulunan dâhili IMU sensöründen alabilmek için kablolar aracilığı ile bir bağlantı kurmuşlardır [3,4].

Açısal konum referans tahmin uygulamaları bağlamında genellikle Euler açıları (dönme (yaw), yunuslama (pitch) ve yalpalama (roll)) gösterimleri kullanılır [5]. İHA'lar içinde bu hareket tanımları geçerlidir. Bu hareket tanımları, ataletsel ölçüm ünitesi (IMU) sensörü ile hesaplanmaktadır. Hareket ve yönelim tespit ve ölçümlerini yapmak için kullanılan sistemlere ataletsel (eylemsizlik) ölçüm sistemleri adı verilmektedir [6]. IMU ivme, açısal hız ve manyetik alan yoğunluğu bilgilerini elde eder. İHA'lar yunuslama, yalpalama, dönme eksenlerinde kararlı hareket edebilmelidir. Çalışmamız kapsamında çok rotorlu IHA için yunuslama, yalpalama, dönme hareketlerini; PID algoritmasının sonuçları ile ağılık ve denge merkezi gibi etmenleri gözlemleyebileceğimiz bir test düzeneği geliştirdik. İHA'dan haricen, yazılımsal hatalar olabileceği göz önünde bulundurulduğundan, elektronik devre tasarlanıp düzeneğin üzerine yerleştirilmiştir. Düzenek üzerinde konumlanan elektronik devrede IMU sensörü, bluetooth modülü ve devrenin kontrol birimi olarak STM32F4DISCOVERY geliştirme kartı kullanılmıştır. IMU sensörü ivmeölçer, jiroskop, manyetometreden oluşmaktadır. Bu üç birim sayesinde veri elde edilir; mikrodenetleyici ile veri işlenir ve hareket eksenlerinin bilgisine ulaşılmış olur. Elde edilen verinin daha kararlı olması için veri füzyonu uygulanır. Veri füzyonu esas olarak bir bilgi bütünleştirmesi problemidir. Bu yöntem çoklu algılayıcıdan gelen verilerin birleştirilerek ilgili durum için tek bir algılayıcı kullanımından daha iyi bir analiz yapılmasına ve daha iyi kararların verilmesini sağlamaktadır [7]. Birçok yöntemle veri füzyonu yapılabilir. Bu çalışma da tamamlayıcı (complementary) filtre kullanılmıștır. Tamamlayıcı filtre, ölçülen sinyal üzerindeki gürültüleri elimine eder [8]. Hareket eksenlerinin bilgisi bluetooth ile bağlantı sağlanacak akıllı telefona gönderilir. Telefon ile düzenek arasında bluetooth bağlantısı kurulduktan sonra proje dâhilinde geliştirdiğimiz mobil uygulamaya (Şekil 4). Giriş yapılarak hareket eksenlerinin bilgisi görüntülenir. Mobil uygulamada hareket eksenlerinin bilgisi dışında üç eksen olmak üzere ivmeölçer, jiroskop ve manyetometreden okunan ișlenmemiş verilerde görüntülenmektedir. Düzeneğin mekanik yapısı, doğru bir analiz için İHA'nın yapabileceği hareketleri kısıtlamaması gerekmektedir. Bu yüzden düzenek tasarımında jiroskop yapısı model alınarak geliştirilmiştir. Jiroskop; yatay düzlem üzerine konumlandırıldığında ve bir kuvvet uygulandığı takdirde, yatay düzlem üzerinde dönüşüne devam etmek yerine, düzlem etrafında dönmeye başlar. Jiroskopun dönmeye başladığı eksen ile Jiroskopun üzerinde durduğu yüzeyin arasındaki açı ne kadar değiştirilirse değiştirilsin, Jiroskopun dönüş ekseni sabit bir şekilde kalır. Bu prensipten yaralanarak modelin orta noktasına insansız hava aracını yerleştirdik. Motorların uyguladığı kuvvetler ile yunuslama, yalpalama, dönme hareketleri araç zarar görmeden ve istenilen esneklikte çok rotorlu insansız hava aracı simüle edilebilmektedir. 


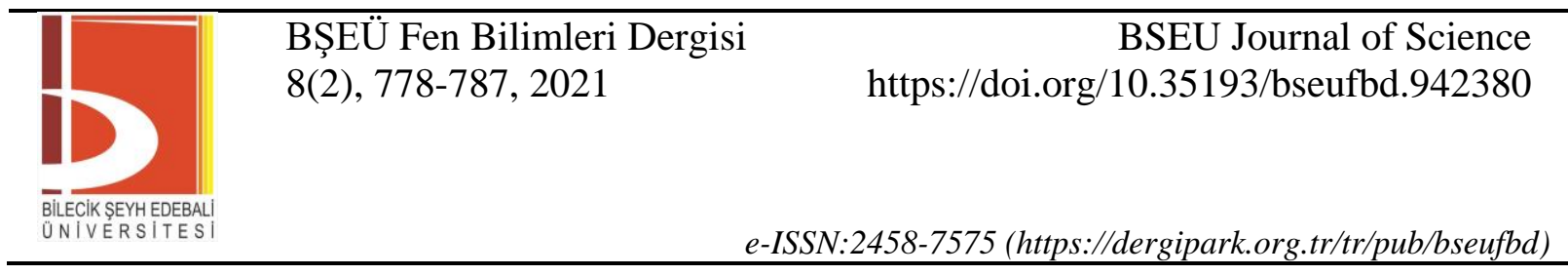

\section{MATERYAL VE METOT}

\section{A. IMU Sensörü}

Temel olarak ivmeölçer, jiroskop ve manyetometre barındıran elektronik bir cihazdır. Hareket, kuvvet ve yönelim bilgisi istenilen uygulamalarda sıklıkla kullanılır. IMU sensörünü oluşturan; ivmeölçer, statik (yer çekimi) ve dinamik (hızlanmaya bağlı olarak değişen) ivmeyi; jiroskop, bir nesnenin, bir eksen etrafında ne kadar hızla döndüğü bilgisini yani açısal hızını ve manyetometre ise manyetik alan yoğunluğunu ölçmeye yarar. Çalışmamızda "MPU9250" IMU sensörü kullanılmıştır. Atalet ölçüm sistemi oluşturulurken atılması gereken ilk adım sensör verilerinin okunması ve okunan bilgilerin anlamlı verilere dönüştürülmesi işlemidir [9]. MPU9250 modülü "SPI" ve "I2C" haberleşme protokollerini kullanabilmektedir. Ayrıca her bileşeni üç eksende veri çıkışı sağlamaktadır. IMU sensörü üzerinde bulunan ivmeölçer, $\pm 1 \mathrm{~g}, \pm 2 \mathrm{~g}, \pm 4 \mathrm{~g}$ (g:Bir kütleye belirli bir durumda etki eden hızlanma. $1 \mathrm{~g}, \quad 9.81 \mathrm{~m} / \mathrm{s}^{2}$ dir) ölçüm aralıklarında; jiroskop, $\pm 100, \pm 250, \pm 500$ derece/saniye ölçüm aralıklarında; manyetometre ise $\pm 4800 \mu \mathrm{T}$ (mikrotesla) ölçüm aralıklarında veri ölçümü yapabilmektedir [10].

\section{B. STM32F4DISCOVERY Geliştirme Kartı}

IMU sensöründen verileri okuyabilmek, bu verileri işlemek ve bluetooth üzerinden akıllı telefona aktarmak gibi işlemleri yönetmek ve denetlemek için bir mikrodenetleyiciye ihtiyaç vardır. Bu ihtiyacı karşılamak için STM32F4DISCOVERY geliştirme kartı kullanılmıştır. Discovery Kart, 32-bit ARM mimarisine sahip STM32F407VG işlemcisini kullanmaktadır. Bu işlemci 168MHz'lik maksimum saat frekansı ile yüksek hızlarda çalışma imkânı sunar. Bu işlemcinin desteklediği haberleşme sistemlerinden olan I2C ve UART protokolleri, IMU sensör ve bluetooth modül ile iletişim için yeterlidir.

\section{Bluetooth Modülü}

Bluetooth, veri aktarımı için geliştirilmiş kısa mesafeli bir iletişim teknolojisidir. Kablosuz iletişìm için 2.4GHz frekansındaki radyo dalgalarını kullanır. Diğer kablosuz iletişim yöntemlerine göre daha az enerji tüketir ve daha ucuzdur. Bluetooth modülleri ile mikrodenetleyici arasında veri alışverişi yapabilmek için UART(Universal Asynchronous Receiver Transmitter) seri haberleşme protokolü kullanılır. Çalışma kapsamında "Bluetooth 2.0" teknolojisini destekleyen HC-05 bluetooth modülü kullanılmıştır. Protokol gereği aynı anda sadece bir cihaz ile bağlantı kurar ve onunla veri transferine izin verir.

\section{Test Düzeneğinin Tasarımı}

Çok rotorlu İHA'lar, motorların ürettiği kuvvetlerin büyüklüklerine göre hareket ederler. Şekil 1'de gösterildiği gibi kuvvetlerin eşitliklerine göre yapılan hareket değişir. Test düzeneği tasarlanırken temel olan yunuslama, yalpalama ve dönme hareketleri göz önünde bulundurulmuştur. Test düzeneğinden beklentiler rahatça gözlem yapılabilmesi için eksenlerde hareket kısıtlaması olmaması, IHA'nın test edilmesi esnasında düzenekten ayrılmaması, düzeneği bulunduğu zeminden hareket ettirmemesidir. Test düzeneği için jiroskop model alınmıştır. Jiroskopun herhangi bir ekseni bir kuvvettin etkisiyle hareket ederken başka bir eksene kuvvet uygulandığında, her iki eksen birbirini etkilemeden, kuvvetin etkisi kalkana kadar hareketlerine devam eder.
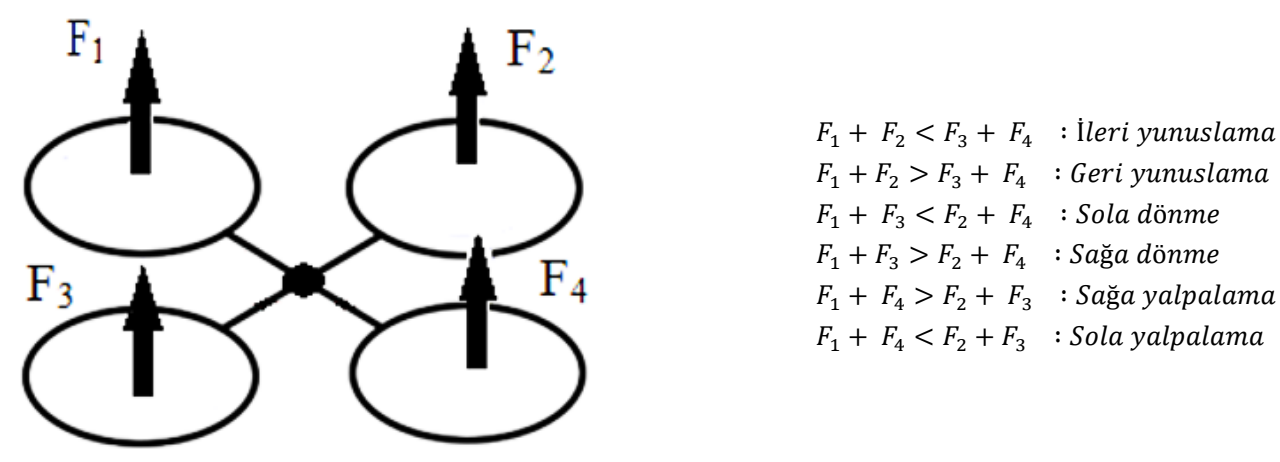

Şekil 1. İHA hareket etme prensibi

Düzeneğin yapı malzemesi olarak hafif olması nedeniyle "kayın-marin", serbest hareketin sağlanması için ise rulmanlar kullanıldı. Kullanılan rulmanlar düzeneklerin orta kısımlarından diğer parça düzenekleri ile 
birleştirildi. İHA'nın yerleştirilmesi için düzeneğin denge noktasına sabitleme parçası yerleştirildi. İHA düzeneğe kelepçeler ile tutturulmaktadır. Test düzeneğinin yapısı, üç eksende de İHA'nın etrafını muhafaza amaçlı saracak şekilde tasarlanmıştır. Test düzeneği tasarımı Şekil2'de gösterilmiştir. İHA, düzenek üzerinde kumanda edildiğinde test mekanizması ile harekete geçer. Test düzeneği üzerinde bulunan IMU sensörü hareket değişimlerini ve eksenlerini algılar. Algılanan değişimin verileri I2C protokolü ile mikrodenetleyici tarafindan okunur. Okunan bu veriler mikrodenetleyicide işlenir ve anlamlı hale getirilir. Veri füzyonu uygulanarak verinin daha kararlı olması sağlanır. Veri okuma ve işleme işlemlerinden sonra, mikrodenetleyici UART protokolü ile HC-05 bluetooth modülü üzerinden elde edilmiş olan bu veriyi alıcı cihaza gönderir.

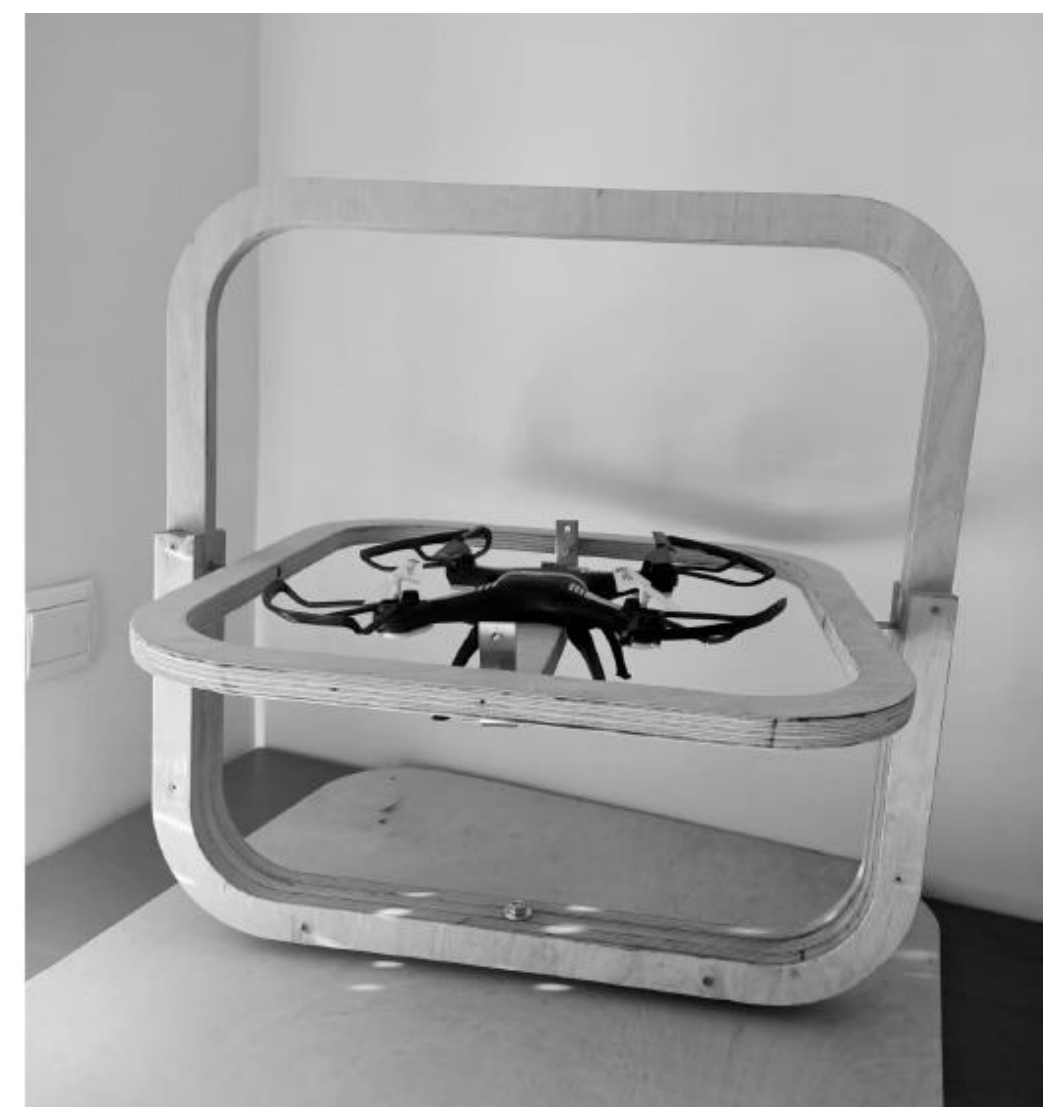

Şekil 2. İHA uçuş test düzeneği

\section{E. Elektronik Devre Tasarımı}

Bluetooth modülü, IMU sensörü ve mikrodenetleyicinin bağlantıları Şekil 3'teki gibi yapılmıştır. I2C ve UART haberleşme protokolleri iki kablo üzerinden iletişimi gerçekleştirir. MPU9250 modülü 3.3V, HC-05 modülü $5 \mathrm{~V}$ besleme gerilimine ihtiyaç duyar. Ayrıca HC-05 modülünün Rx bacağındaki gerilim $5 \mathrm{~V}$ seviyesindedir. STM32F4DISCOVERY geliştirme kartının bacakları 3.3V'a duyarlı olduğundan dirençler ile basit bir gerilim bölücü uygulanmıştır. STM32F407VG işlemcisinin giriş çıkış pinlerinin çoğu 5V'a toleranslı olmasına rağmen yine de gerilim bölücü kullanılmıştır. Devre üzerindeki bağlantılar;

PC7 $\rightarrow$ HC-05 TX

PC6 $\rightarrow$ HC-05 RX
$\mathrm{PB} 7 \rightarrow \mathrm{MPU} 9250$ SDA

$\mathrm{PB} 6 \rightarrow \mathrm{MPU} 9250 \mathrm{SDL}$

şeklindedir. 


\begin{tabular}{|c|c|c|}
\hline & $\begin{array}{l}\text { BŞEÜ Fen Bilimleri Dergisi } \\
8(2), 778-787,2021\end{array}$ & $\begin{array}{r}\text { BSEU Journal of Science } \\
\text { https://doi.org/10.35193/bseufbd } 942380\end{array}$ \\
\hline VEERS & & 2458-7575 (https://dergipark.org.tr/tr/pub/bseufbd) \\
\hline
\end{tabular}

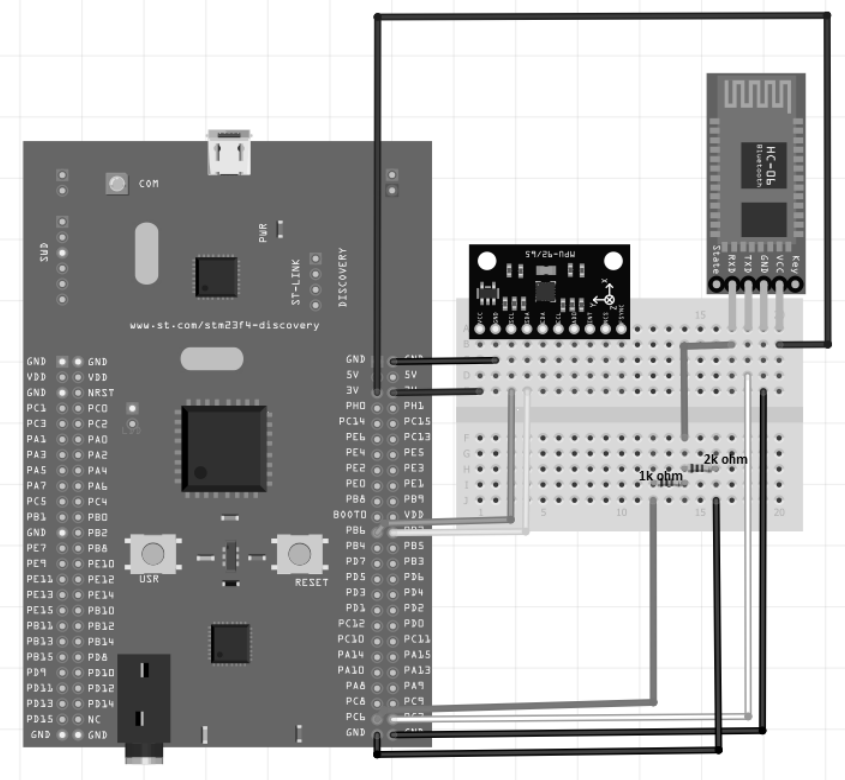

Şekil 3. Devre bağlantı şeması

\section{F. Mobil Uygulama}

Test verilerinin anlık olarak izlenebilmesi için bluetooth terminal uygulaması gerçekleştirilmiştir. Akıllı telefonun ayarlarından bluetooth özelliği açıldıktan sonra test düzeneği üzerindeki HC-05 bluetooth modülü ile eşleştirilir. Eşleşme sağlandıktan sonra uygulama üzerinden bluetooth cihazları görüntülenir ve eşleştirilen HC-05 bluetooth modülü seçildikten sonra bağlantı sağlanır ve veri alış-verişi başlamış olur.Şekil4'te de görüleceği gibi İHA hareket bilgisi net bir şekilde uygulama üzerinden izlenebilmektedir.

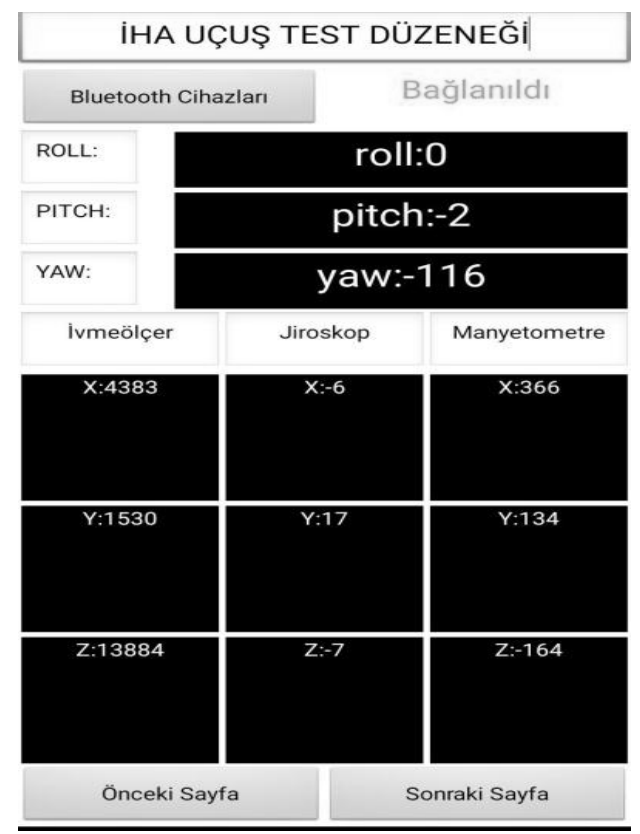

Şekil 4. Mobil uygulama ekran görüntüsü 


\section{G. IMU Sensörü̈nden Veri Okunması ve İşlenmesi}

Kartezyen koordinat sisteminde, $\mathrm{X}$ ekseni etrafında saat yönünde dönüş, yalpalama (+); Y ekseni etrafında saat yönünde dönüş, yunuslama $(+)$; $Z$ ekseni etrafında saat yönünde dönüş, dönme $(+)$ olarak tanımlanır [11]. Eksenler ile hareketlerin birbiri ile olan bağıntısı Şekil 5’te gösterilmektedir [12].

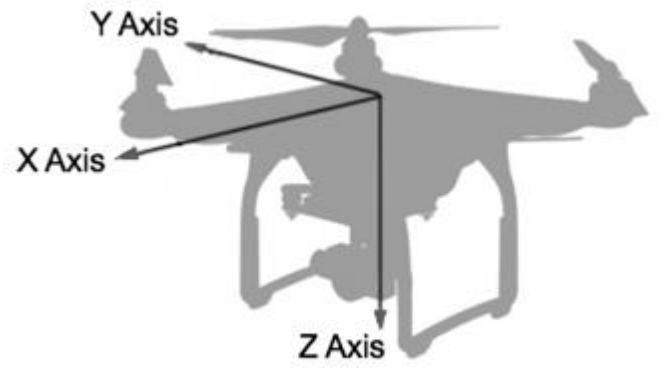

Şekil 5. İHA üzerinde eksenlerin gösterimi [12]

$\mathrm{Bu}$ dönüş hareketlerinin hesaplanması ivmeölçer ve jiroskoptan elde edilen veriler ile yapılmıştır. Manyetometre dönme hareketinin hesaplanması için gereken veriyi elde etmek için kullanılmıştır. İvmeölçerden bu dönüş hareketlerinin açılarını elde etmek için küresel koordinat sisteminden yararlanılır. Küresel koordinat sisteminde $\mathrm{Z}$ ekseni ile XY düzlemi ve X-Y eksenleri arasında iki tane açı vardır. İvmeölçerden okunan kartezyen ivme verisi küresel-kartezyen koordinat sistemi dönüşüm formülleri ile işleme alındığında yunuslama ve yalpalama hareketlerinin dönüş açıları elde edilir. Küresel-Kartezyen Koordinat Sistemi Dönüşüm Formülleri, 2.1, 2.2 ve 2.3 formülleri ile verilmiştir.

Kartezyen koordinat sisteminde $(0,0,0)$ noktasından herhangi bir $(\mathrm{x}, \mathrm{y}, \mathrm{z})$ noktasına çizilen vektör; küresel koordinat sisteminde " $\Gamma$ " sembolü ile gösterilir Denklem (1)' deki gibi hesaplanır.

$$
\Gamma=\sqrt{x^{2}+y^{2}+z^{2}}
$$

Kartezyen koordinat sisteminde XY düzlemi ile $\mathrm{Z}$ ekseni arasında bulunan bir vektörün $\mathrm{Z}$ ekseni ile yaptığı açı " $v$ "” sembolü ile gösterilir ve Denklem(2)' de verildiği gibi hesaplanır.

$$
v^{\prime}=\tan ^{-1} \frac{\sqrt{x^{2}+y^{2}}}{z}
$$

Denklem(3)' te $\mathrm{X}$ ve $\mathrm{Y}$ eksenleri arasında kalan bir vektörün $\mathrm{X}$ ekseni ile yaptı̆̆ açının hesaplanması verilmiş̧ir.

$$
\Phi^{\prime}=\tan ^{-1} \frac{y}{x}
$$

" $\Phi$ "” açısının hesaplanması ile yalpalama, " $v$ " açısının hesaplanması ile yunuslama hareketlerinin büyüklüğ̈̈ elde edilir.

Jiroskoptan elde edilen açısal hız verisi, eksen etrafındaki dönüşün hızını ifade eder. Jiroskop verilerinden yunuslama, dönme ve yalpalama hareketlerinin açısı Şekil 6.'da gösterildiği gibi elde edilir. Şekil 6'daki algoritmada "dt" değişkeni eksen etrafındaki dönüş süresidir. Eksen etrafındaki dönüşün başladığı an ile ölçümün yapıldığı son anın farkı olarak hesaplanır. İlk veri okuması sonrası gelen her iki veri arasında geçen süre olarak tanımlanmaya devam eder. 1000 kat sayısına bölünerek milisaniye-saniye dönüşümü yapılması amaçlanmıştır. Jiroskoptan okunan açısal hız değerleri(algoritmadaki gyr_x, gyr_y, gyr_z değişkenleri) ile eksen etrafindaki dönüş süresinin skaler çarpımı yunuslama, yalpalama, dönme hareketlerinin açısının büyüklüğünü elde etmemizi sağlar. Açı değişimi bir değişkene kaydedilir ("get_last_x_angle(), ..”). Bu değişken formüle toplam şeklinde yazılarak son konumdaki açıyı hesaplamamızı sağlar. 


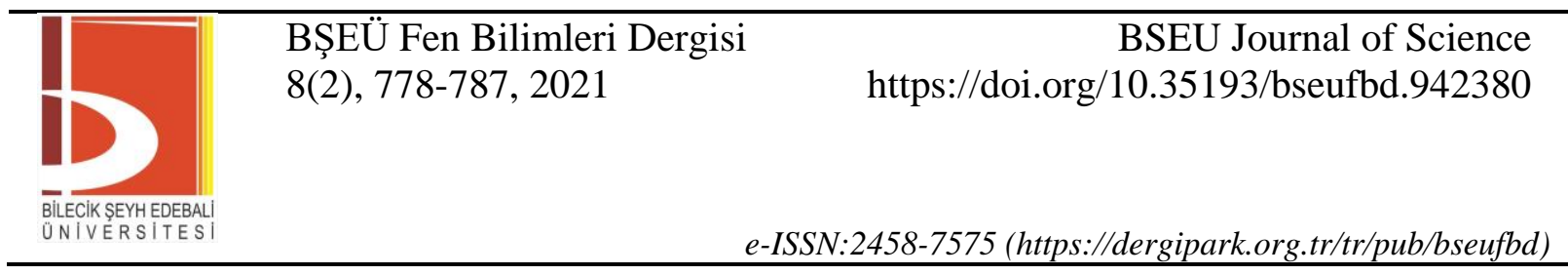

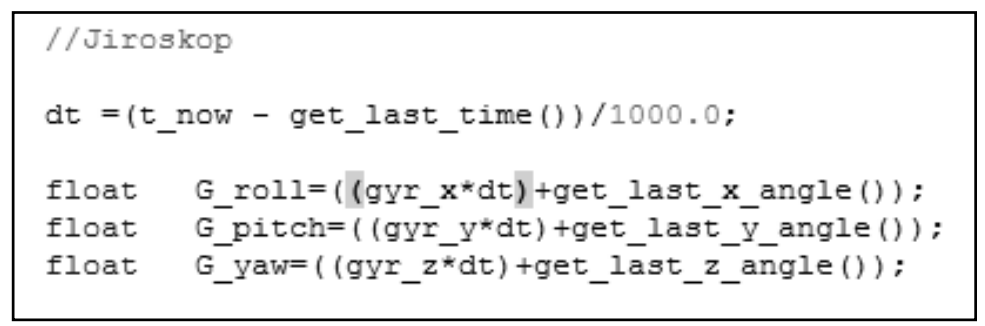

Şekil 6.Jiroskop İle Hareket Açılarının Hesaplanmasını İçeren Kod Parçası

IMU sensörü içinde bulunan ivmeölçer yüksek frekanslarda, jiroskop düşük frekanslarda daha fazla gürültüler barındırır. Daha az gürültü içeren kararlı veriyi elde etmek için veri füzyonu kullandık. Veri füzyonu, farklı kaynaklardan elde edilen bilginin bütünleştirilmesi için kullanılan yöntemlerin genel ismidir. İvmeölçer ve jiroskoptan okunan veriler ile hesaplanan yunuslama ve yalpalama (G_roll, A_roll, G_pitch, A_pitch) ile jiroskop ve manyetometreden okunan veriler ile hesaplanan dönme (G_yaw, M_yaw) hareketlerine veri füzyonu uygulayarak bütünleştirme işlemini gerçekleştirdik ve daha kararlı bir veri elde ettik.

Veri füzyonu için birçok metot vardır. Bu çalışma kapsamında "tamamlayıcı filtre" kullanılmıştır. Tamamlayıcı Filtre yapısı hem jiroskop için yüksek geçiş filtresi hem de ivmeölçer için düşük geçiş filtresi içerir [13]. Şekil 7'de tamamlayıcı filtre için yazılan kod parçası gösterilmiş̧ir. Veri füzyonunun, bir veri bütünleştirmesi olduğundan ve bu çalışma kapsamında veri füzyonu için tamamlayıcı filtre kullandığımızdan bahsetmiştik. Tamamlayıcı filtrede, jiroskop çıkışından açı değeri alabilmek için sensör çıkışının zamana göre integrali alınır [5]. "dt" değişkeni zaman bilgisini barındırır. Şekil 7'deki tamamlayıcı filtre algoritmasında "HP_Weight" olarak isimlendirilen değişken ile jiroskop çıkışına yüksek geçiren, ivmeölçer ve manyetometre çıkışına alçak geçiren filtre uygulanıp verilerin toplanması ile veri bütünleştirmesi gerçekleştirilmiş olur.

"HP_Weight" 0 ile 1 arasında bir değeri vardır. İvme ölçerin yüksek frekanslarını, jiroskopun düşük frekanslarını filtreleyebilmek için gürültünün en az gözlemlendiği, 0.98 değeri yapılan denemeler sonucunda ampirik olarak belirlenmiştir.

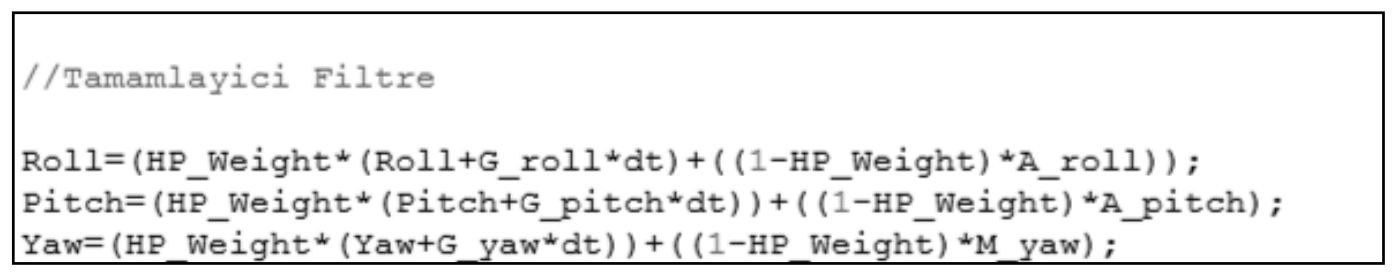

Şekil 7. Tamamlayıcı filtrenin kod parçası

\section{BULGULAR VE TARTIŞMA}

Yaptığımız çalışmada IMU sensöründen veri okunmuş ve okunan bu veriler havacılıktaki yalpalama, yunuslama ve dönme hareketleri cinsinden ifade edilmiştir

Şekil 8, IMU sensörünün $X, Y$ ve $Z$ eksenlerinden ölçülen ivmenin grafiğidir. Grafikteki eğriler ivme büyüklüğü, sapma ve gürültüleri barındırır. İvme, Denklem (4)'teki gibi birim kütle başına kuvvet olarak düşünülebilir [14].

$$
a=\frac{F}{m}
$$

Dünyanın kütle çekim kuvvetinin etkisinden dolayı ivmeölçer durağan haldeyken yerçekimi ivmesini ölçer. İvmeölçer sürekli olarak yerçekimi kuvvetinin etkisi altında olduğundan; yerçekimi ivmesi $\mathrm{X}, \mathrm{Y}$ ve çoğunlukla $\mathrm{Z}$ eksenine ait ivmenin eğrisine dâhildir [15]. X, Y ve $\mathrm{Z}$ eksenlerindeki yerçekimi ivmesi etkisinin büyüklüğü ölçümün yapıldığı referans noktasının eğimine bağlı olarak değişmektedir [14]. İvme verisinde olduğu gibi manyetometre ve jiroskop verileri de gürültü içermektedir. 


\begin{tabular}{|c|c|c|}
\hline & $\begin{array}{l}\text { BŞEÜ Fen Bilimleri Dergisi } \\
8(2), 778-787,2021\end{array}$ & $\begin{array}{r}\text { BSEU Journal of Science } \\
\text { https://doi.org/10.35193/bseufbd.942380 }\end{array}$ \\
\hline & & :2458-7575 (https://dergipark.org.tr/tr/pub/bseufbd) \\
\hline
\end{tabular}

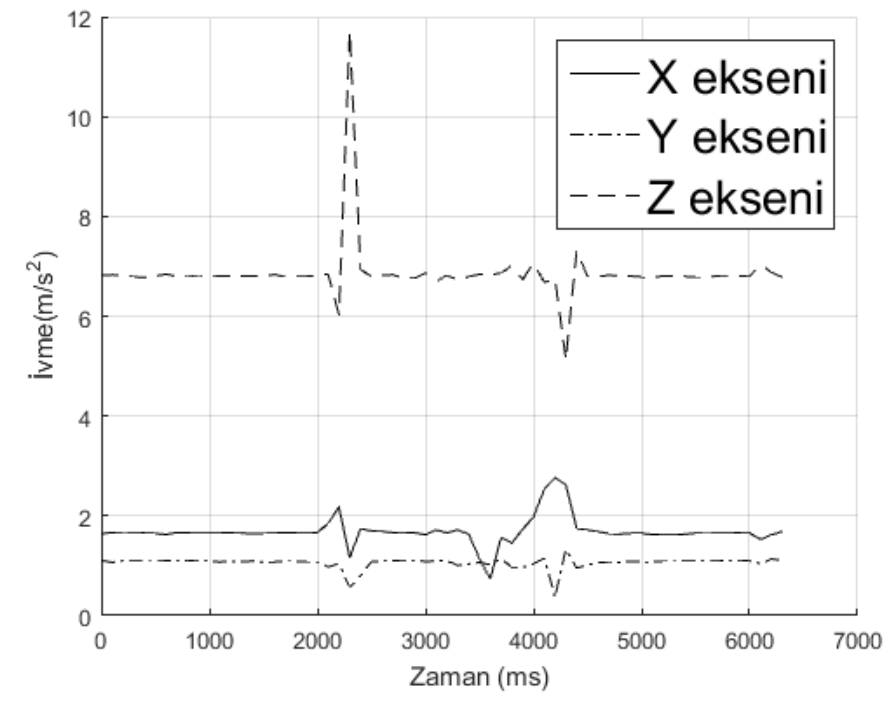

Şekil 8. X, Y ve Z eksenlerinde ivme

IMU sensöründen elde edilen işlenmemiş veriler ile yunuslama, yalpalama, dönme hareketleri hesaplanır. Elde edilen, hareketlerin büyüklüğüne ait değerler de gürültü içermektedir. Sırasıyla saat yönünde ve saat yönünün tersinde yalpalama hareketinin grafiği Şekil 9'daki gibidir. Eğrideki gürültünün giderilmesi için tamamlayıcı filtre uygulanmıştır.

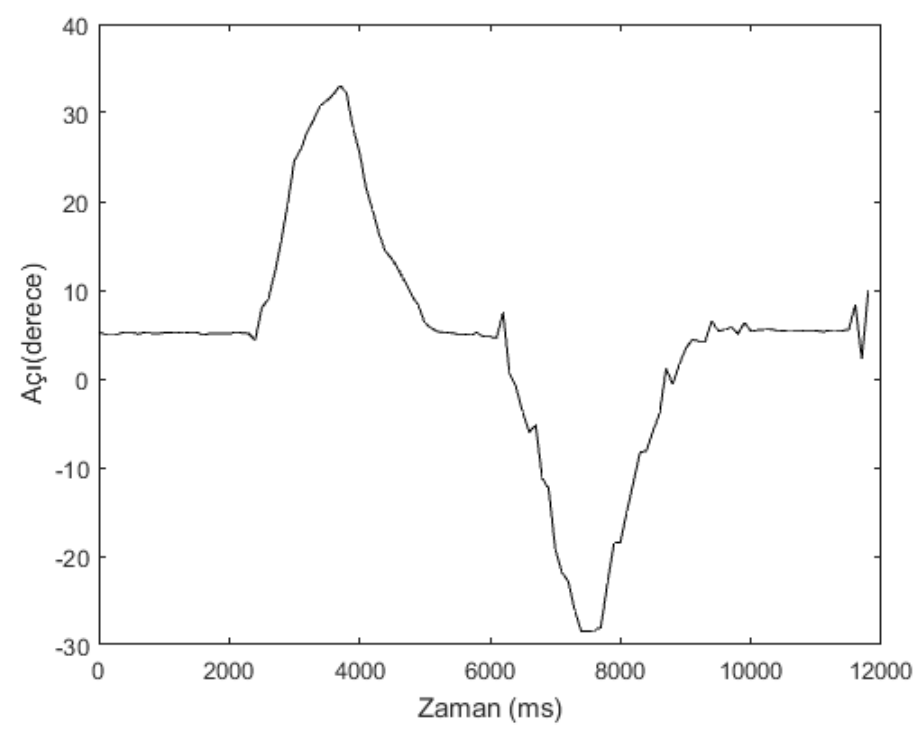

Şekil 9. Filtre uygulanmamış yalpalama hareketi grafiği

Tamamlayıcı filtre uyguladıktan sonraki yalpalama hareketine ait grafik Şekil 10'da verilmiştir. 

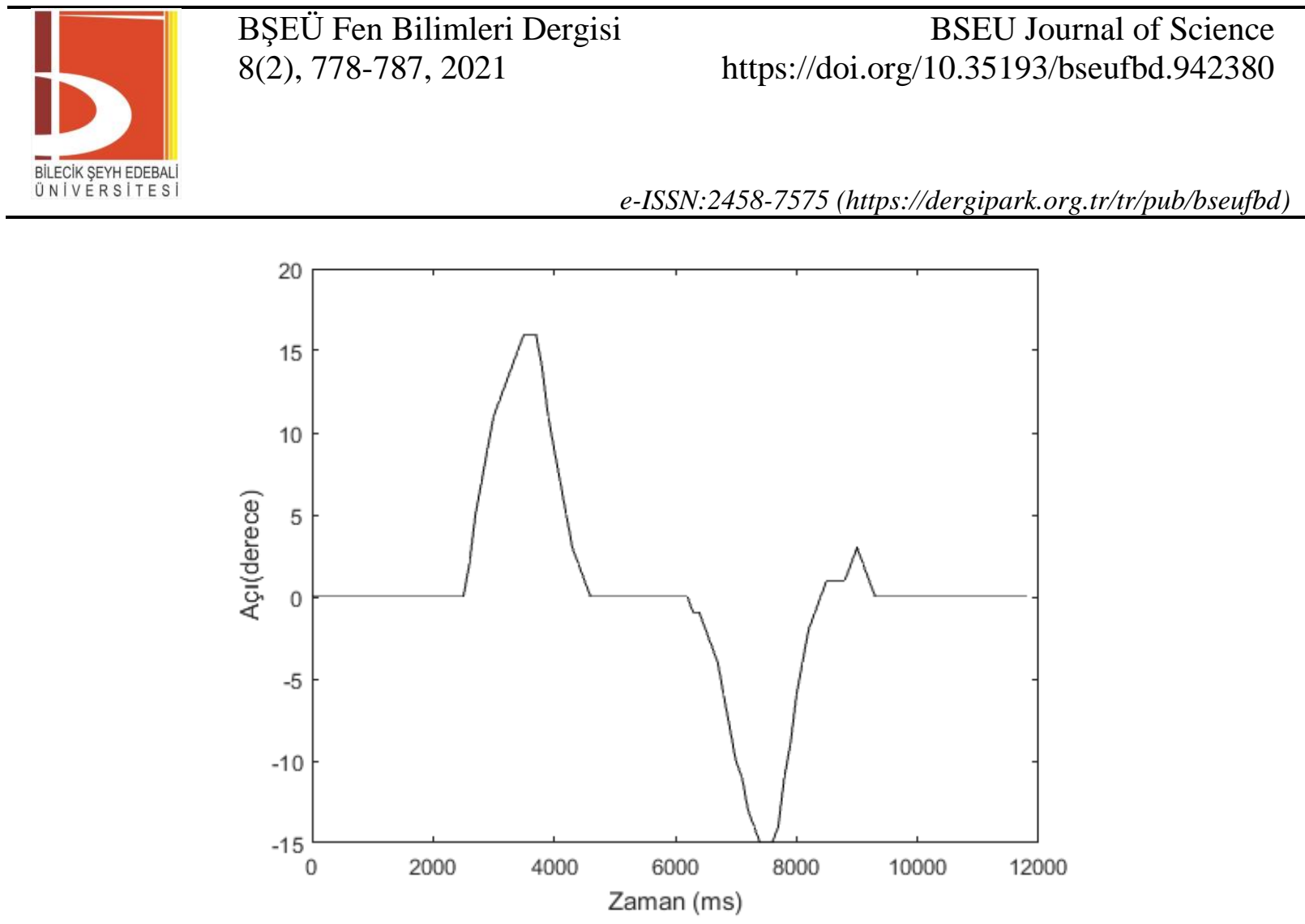

Şekil 10. Filtre uygulanmış yalpalama hareketi grafiği

Şekil 9'da gösterilen yalpa hareketinin grafiğinde gözüktüğü gibi açı eksenindeki kayma ve eğrideki osilasyonlar, yunuslama ve dönme hareketlerinde de gözlemlenmiştir. Tamamlayıcı filtre sayesinde veriler daha kararlı hale getirilmiş ve sonuç olarak Şekil 10'daki yalpalama hareketine ait grafik elde edilmiş; açı eksenindeki kayma giderilmiş ve eğrideki osilasyonların azalması dönme ve yunuslama hareketlerinde de gözlemlenmiştir.

İHA uçuş test düzeneğinde kalman filtresi gibi farklı yazılımsal filtreler kullanılarak veri füzyonu geliştirilmesi yapılabilir. Hedef alınan bir hareket açısı olmadığından yani yazılım istenilen bir açıya gitme fonksiyonunu gerçekleştirmediğinden; bulunduğu konumdaki açı değerini okuduğundan hata oranı hesaplaması yapılmamıştır. Mobil uygulama ara yüzünde değişikliğe gidilerek verileri kaydetme özelliği eklenebilir. Daha büyük boyutlu İHA'lar için test düzeneğinde yeniden boyutlandırılmaya gidilmelidir, fakat elektronik kart donanımında herhangi bir değişikliğe ihtiyaç yoktur. Test düzeneğinde, malzeme ağırlığının hareket yönlerine bir etkisi yoktur. Malzeme ağırlığı hareket kabiliyeti ile değil itki kuvveti ile ilişkilidir. Gövde malzemesinin ağırlığı arttıkça istenilen açıya ulaşmak için motorların uyguladığı kuvvet artacağından daha fazla itki üreten İHA'lar test edilebilmektedir. Düşük itki üreten İHA’ların da test edilebilmesi için gövde malzemesinin ağırlığı minimum seviyeye çekilebilir.

\section{SONUÇ}

$\mathrm{Bu}$ çalışma sonucunda insansız hava aracı üretimi sırasında, hava aracının çeşitli aşamalarda temel uçuş testlerinin ve simülasyonlarının yapılmasının sağlanacağı mikrodenetleyici kontrollü İHA uçuş test düzeneği geliştirilmiştir.

Bu alandaki yapılan diğer çalışmalar incelendiğinde İHA’nın farklı eksenlerdeki hareketlerini ölçmeye yarayan çeşitli test düzenekleri ile karşılaşmak mümkündür. Veri çıktısı sağlayan düzenekler, veri ölçme işlemini IHA üzerinde bulunan dâhili IMU sensöründen yapmaktadır. Bu yöntem izlendiğinde hareket açısının hatalı olması durumunda bu hatayı görüntüleyebilmek mümkün olmamaktadır. Bizim çalışmamız da İHA üreticisinin yazılımsal hatalar ile karşılaşabileceği göz önünde bulundurulduğundan insansız hava aracından harici olarak bir devre kurulup düzeneğin üzerine yerleştirilmiş ve devrenin ölçümlerinin gözlemlenebilmesinin sağlanacağı mobil uygulama tasarlanmıştır. Bu sayede hedeflenen veriler ile gerçekteki verilerin ne olduğu kıyaslanabilecek ve yazılımın güvenirliliği kontrol edilebilecektir. İHA tasarım ve yazılımcıları bu verileri kullanılarak, kendi tasarımlarını ve programlarını, deneme ve düzeltme imkânına sahip olacaktır.

İnsansız hava aracını üretecek kişiler ya da gruplar için test aşamasının uçuş esnasında değil de test düzeneği üzerinde yapılması, yaşanacak olası olan kazaların önüne geçilmesini sağlayacaktır. Olası kazalar sonucu inansız hava aracının gövde, kol, pervane gibi parçaları hasar alabileceği için üretim maliyetleri artabilmektedir. 
Mikrodenetleyicili İHA Uçuş Test düzeneği sayesinde, insansız hava aracı test aşamasında iken herhangi bir hasar almayacağı için tasarım ve ar-ge maliyetleri düşecektir. Aynı zamanda yazılım aşamasında, yazılımın sürekli olarak test edilmesi ve tepkilerin gözlemlenmesi gerektiğinden tasarım ve test aşamasını hızlandırmaktadır.

\section{KAYNAKLAR}

[1] Yüzgeç, U., Ökten, İ., Üçgün, H., Gün, A. R., Türkyılmaz, T., Kesler, M., ... \& Uçar, G. (2016). Development of the Test Platform for Rotary Wing Unmanned Air Vehicle. Bilecik Şeyh Edebali Üniversitesi Fen Bilimleri Dergisi, 3(2), 18-24

[2] Ökten, İ. (2016). Dört rotorlu döner kanat insansız hava aracı test düzeneği geliştirilmesi, Yüksek Lisans Tezi, Bilecik Şeyh Edebali Üniversitesi, Fen Bilimleri Enstitüsü, Bilecik.

[3] Euraka Dynamic, 5 Reasons Your Company Needs a FFT GYRO. https://eurekadynamics.com/2021.12.10.5-reasons-your-company-needs-a-fft-gyro/, (Erişim tarihi: 08.12.2020)

[4] Euraka Dynamic, FFT GYRO 250. https://eurekadynamics.com/fft-gyro-250/, (Erişim tarihi: 08.12.2020)

[5] Özkan, O. (2019). Sensör Füzyonu Algoritmaları ile Açısal Konum Referans Sistemi Tasarımı. Bayburt Üniversitesi Fen Bilimleri Dergisi, 2(1), 93-103.

[6] Özkan, E. (2010). Üç Boyutlu Uzayda Hareket Algllama, Tespit ve Kestirimi İçin Genişletilebilir Bir Donanım Tasarımı, Yüksek Lisans Tezi, İstanbul Teknik Üniversitesi, Bilişim Enstitüsü, İstanbul.

[7] Biroğul, S., Sönmez, Y., \& Güvenç, U. (2007). Veri füzyonuna genel bir bakış. Politeknik Dergisi, 10(3), 235-240.

[8] Okudan, M. E. (2019). Navigasyon hassasiyetini arttırmak için ataletsel ölçüm birimine tamamlayıcı filtre uygulanması. Yüksek Lisans Tezi, İstanbul Teknik Üniversitesi, Fen Bilimleri Enstitüsü, İstanbul.

[9] Altın, C. (2013). Dört rotorlu insansız hava aracının yükseklik ve konum kontrolü. Yüksek Lisans Tezi. Yozgat Bozok Üniversitesi Fen Bilimleri Enstitüsü, Yozgat.

[10 ] IMU Sensörüne ait Veri Yapră̆ , 2016, MPU9250, Invensense

[11] Tran, L. D. (2017). Data Fusion with 9 degrees of freedom Inertial Measurement Unit to determine object's orientation.

[12] DJI, (2020). https://developer.dji.com/mobilesdk/documentation/introduction/flightController_concepts.html. (Erişim tarihi: 08.12.2020)

[13] Altın, C. \& Er, O. (2015). Complementary Filter Application for Inertial Measurement Unit. Electronic Letters on Science and Engineering, 11(2), 20-25.

[14] Colton, S. (2007). The balance filter: a simple solution for integrating accelerometer and gyroscope measurements for a balancing platform. Chief Delphi white paper, 1.

[15] Pınar, D. (2017). Ívmeölçer sinyallerinin ileri yöntemlerle analizi, Yüksek Lisans Tezi, Başkent Üniversitesi, Fen Bilimleri Enstitüsü, İstanbul. 